\title{
IMPLEMENTATION OF CHARACTER EDUCATION VALUES IN ISLAMIC SCHOOL INTEGRATED TO IBNU ABBAS KEBUMEN
}

\author{
Indri Novianti, Lutfiana Rahmayanti, Rizki Isnaeni Putri, Siti Fatimah \\ Universitas Sebelas Maret \\ indrinovianti@student.uns.ac.id
}

\section{Article History}

accepted 30/09/2018

approved $12 / 10 / 2018$

published 30/10/2018

\section{Keywords}

Character education values, SDIT Ibnu

Abbas

\begin{abstract}
This study aims to: a) find out the method of implementing the values of selected character education such as religious, honest, diligent, disciplined, and caring / responsible; b) knowing the religious behavior, honesty, diligence, discipline, and caring / responsibility of students in SDIT Ibn Abbas; and c) knowing the barriers to the application of character education values and solutions sought by the teacher. Research is a qualitative descriptive study by collecting data through interviews and questionnaires. The results of observation showed that the religious aspect was $54.73 \%$ with the category "enough", honest aspects $62.55 \%$ with the category "enough", aspects of diligence $82.30 \%$ with the category "good", disciplinary aspects $82.71 \%$ with the category "good" and environmental aspects of $63.73 \%$ with the category "enough". The obstacle experienced by the teacher is when the planting taught by the teacher is not in harmony with the one at home. So that the solution sought by the teacher is to communicate more deeply with students and parents of students / guardians of students.
\end{abstract}

Social, Humanities, and Education Studies (SHEs): Conference Series https://jurnal.uns.ac.id/shes

p-ISSN 2620-9284

e-ISSN 2620-9292 


\section{PENDAHULUAN}

Kemajuan suatu negara terletak pada karakter yang dimiliki bangsa tersebut. Karakter merupakan suatu hal yang penting dan mendasar. Karakter adalah tabi'at, watak, sifat - sifat kejiwaan, akhlak atau budi pekerti yang membedakan seseorang dari yang lain. Di Indonesia karakter sudah ditanamkankan dalam dunia pendidikan. Pendidikan tersebut dinamakan pendidikan karakter.

Pendidikan karakter adalah pendidikan yang memberikan nilai-nilai, budi pekerti, moral, ataupun pendidikan yang membentuk watak seseorang dengan tujuan dapat mengembangkan kemampuan peserta didik agar menjadi lebih baik dan mengimplementasikannya dalam kehidupan sehari-hari dengan sepenuh hati, karena baik buruknya suatu negara tergantung dari karakter bangsanya (Buchory dalam Sofiawati dan Fadhillah, 2018:281). Menurut Ratna Megawangi (dalam Kesuma, Cepi, Johar:2013) pendidikan karakter adalah sebuah usaha untuk mendidik anak - anak agar dapat mengambil keputusan dengan bijak dan mempraktikannya dalam kehidupan sehari - hari, sehingga mereka dapat memberikan kontribusi yang positif kepada lingkunganya.

Di Indonesia kesadaran akan pendidikan karakter telah ada di dalam tujuan pendidikan nasional Indonesia. Dalam Undang-undang No 20 Tahun 2003 tentang Sistem Pendidikan Nasional pasal 3 bahwa fungsi Pendidikan Nasional adalah mengembangkan kemampuan dan membentuk watak serta peradapan bangsa yang bermartabat dalam rangka mencerdaskan kehidupan bangsa; dan tujuan pendidikan nasional untuk mengembangkan potensi peserta didik agar menjadi manusia yang beriman dan bertakwa kepada Tuhan Yang Maha Esa, berakhlak mulia, sehat, berilmu, cakap, kreatif, mandiri, dan menjadi warga negara yang demokratis serta bertanggung jawab. Ini berarti bahwa pendidikan tidak hanya membentuk insan Indonesia yang cerdas, namun juga berkepribadian atau berkarakter, dengan harapan agar nantinya akan lahir generasi bangsa yang tumbuh dan berkembang dengan karakter yang bernafas nilai-nilai luhur bangsa dan agama.

Sejalan dengan tujuan pendidikan tersebut presiden Indonesia $2014-2019$ Ir. H. Joko Widodo juga mencanangkan 18 nilai - nilai Pancasila dalam pendidikan karakter yang harus ditanamkan kepada peserta didik, yaitu nilai - nilai religius, jujur, toleran, disiplin, bekerja keras, kreatif, mandiri, demokratif, rasa ingin tahu, semangat kebangsaan, cinta tanah air, menghargai prestasi, komunikatif, cinta damai, gemar membaca, peduli lingkungan, peduli sosial, dan bertanggungjawab (Suryadi dalam Buletin BSNP:2017).

Mengingat pentingnya pendidikan karakter bagi bangsa Indonesia banyak lembaga - lembaga pendidikan menuangkan penerapan nilai - nilai karakter pada visi dan misi lembaganya. Namun pada kenyataannya pelaksanaan visi dan misi pendidikan karakter tersebut tidak dibarengi dengan implementasi yang optimal. Seperti yang dikemukakan oleh Sofiawati dan Fadhillah (2018:281) bahwa salah satu permasalahan yang sedang mencuat ke permukaan di dunia pendidikan di Indonesia saat ini yakni permasalahan yang berhubungan dengan pendidikan karakter. Hal ini ditandai dengan maraknya tindakan kriminalitas yang dilakukan oleh pelajar. Tidak hanya itu, adanya trend-trend kekinian yang tidak mendidik serta perkembangan media social dan teknologi juga semakin mengikis moral anak bangsa.

Menurut Ketua (KPAl) Komisi Perlindungan Anak Indonesia H.M Asrorun Niam Sholeh dalam Catatan Akhir Tahun di kantor KPAI, Rabu (30/12/2015) terdapat peningkatan kasus anak yang menjadi pelaku kekerasan. Pada tahun 2014, tercatat 67 kasus anak yang menjadi pelaku kekerasan. Sementara pada 2015 menjadi 79 kasus. Selain itu, anak sebagai pelaku tawuran mengalami kenaikan dari 46 kasus di tahun 2014 menjadi 103 kasus di 2015. Kementrian Kesehatan RI 2017 juga meyatakan terdapat $3,8 \%$ pelajar dan mahasiswa yang menyatakan pernah menyalahgunakan narkotika dan obat berbahaya. 
Kasus diatas terjadi karena banyak dari mereka yang tidak mengamalkan nilainilai moral serta nilai-nilai keagamaan dengan baik. Sehingga sekarang ini banyak orangtua lebih mempercayakan pendidikan anak ke pendidikan yang berbasis Islam mendetail dan pelaksanaannya kurang intensif jika dibandingkan dengan sekolah yang berbasis akidah atau islam. Karena di sekolah umum penanaman nilai-nilai moral dan keagamaan masih kurang. Sekolah Dasar Islam Terpadu (SDIT) merupakan contoh sekolah yang mengimplementasikan pendidikan akhlak kepada para siswa-siswinya dalam pergaulan hidup sehari-hari baik di lingkungan sekolah maupun di lingkungan rumahnya (Agustina, Irawan, dan Yunisca, 2013).

Sekolah Dasar Islam Terpadu (SDIT) Ibnu Abbas merupakan salah satu sekolah dasar di Kebumen yang berupaya melaksanakan nilai-nilai pendidikan karakter secara nyata yang terlihat dari visi dan misinya yaitu mandiri, sholeh, dan prestasi. Sekaligus kurikulum yang diterapkan dalam SDIT Ibnu Abbas bukan hanya kurikulum umum standar pemerintah saja, namun juga kurikulum keislaman yang dikembangkan oleh sekolah. Menurut Kerr et al (Thapa dan Jonathan, 2013) Studi tentang implementasi program pendidikan karakter menunjukkan bahwa program yang paling efektif adalah program yang dimasukkan ke dalam kurikulum sekolah dan dikembangkan secara holistik dengan komunitas sekolah.

Berdasarkan latar belakang di atas maka penulis membuat rumusan masalah dalam artikel ini adalah sebagai berikut:

1. Bagaimana proses implementasi nilai - nilai pendidikan karakter religius, jujur, tekun, disiplin, dan peduli lingkungan di SDIT Ibnu Abbas?

2. Bagaimana perilaku nilai - nilai pendidikan karakter religius, jujur, tekun, disiplin, dan peduli lingkungan di SDIT Ibnu Abbas?

3. Bagaimana hambatan serta solusi implementasi nilai - nilai pendidikan karakter religius, jujur, tekun, disiplin, dan peduli lingkungan di SDIT Ibnu Abbas?

\section{METODE}

Penelitian ini merupakan penelitian kualitatif yang bersifat diskriptif dengan teknik pengumpulan non tes yaitu pengisian angket dan wawancara. Pengambilan data dilakukan melalui pengisian angket dan wawancara. Alat ukur yang digunakan berupa lembar angket dan lembar wawancara. Objek penelitian atau biasa disebut sampel penelitian diambil secara acak dari semua populasi yang ada di SD Islam Terpadu Ibnu Abbas Kebumen. Teknik analisis data menggunakan analisis frekuensi Skala Likert. Skala Likert adalah digunakan untuk mengukur sikap, pendapat, dan persepsi seseorang atau sekelompok orang tentang fenomena sosial. Penskoran menggunakan skala Likert yang sudah dimodifikasi dengan tiga alternatif jawaban, yaitu : (a) selalu, (b) kadang-kadang, (c) tidak pernah.

Tahap penelitian dimulai dengan pengisian lembar angket yang diisi oleh siswa untuk mengetahui secara umum perilaku religius, jujur, tekun, disiplin, dan peduli lingkungan siswa di SD Islam Terpadu Ibnu Abbas Kebumen. Sampel yang diambil untuk mengisi lembar angket jumlah total siswa 81 siswa.

Tahap selanjutnya adalah wawancara dengan guru dan kepala sekolah. Wawancara dilakukan untuk mengetahui secara umum implementasi nilai-nilai pendidikan karakter terpilih seperti Religius, jujur, tekun, disiplin, dan peduli lingkungan. Serta mengetahui hambatan penerapan nilai-nilai pendidikan karakter dan solusi yang diupayakan oleh guru dan kepala sekolah.

\section{HASIL DAN PEMBAHASAN}

Penelitian ini dilakukan melalui dua tahap. Tahap pertama yaitu observasi dengan pengisian lembar angket oleh siswa. Mengambil beberapa sampel siswa untuk mengisi lembar angket sejumlah 81 siswa. Hasil observasi pengisian angket tertera dalamTabel 1. berikut: 
Tabel 1. Persentase hasil observasi angket

\begin{tabular}{|c|c|c|c|c|}
\hline \multirow[b]{2}{*}{ Aspek } & \multirow[b]{2}{*}{ Pernyataan } & \multicolumn{3}{|c|}{ Persentase } \\
\hline & & Selalu & $\begin{array}{l}\text { Kadang- } \\
\text { kadang }\end{array}$ & $\begin{array}{c}\text { Tidak } \\
\text { Pernah }\end{array}$ \\
\hline \multirow{4}{*}{ Religius } & $\begin{array}{l}\text { 1. Berdoa sebelum belajar } \\
\text { dan asmaul husna }\end{array}$ & $48,15 \%$ & $43,21 \%$ & $8,64 \%$ \\
\hline & $\begin{array}{l}\text { 2. Melaksanakan shalat } \\
\text { dhuha }\end{array}$ & $61,73 \%$ & $38,27 \%$ & $0,00 \%$ \\
\hline & $\begin{array}{l}\text { 3. Melaksanakan shalat wajib } \\
\text { (dzuhur dan ashar) } \\
\text { berjamah di masjid sekolah }\end{array}$ & $54,32 \%$ & $37,04 \%$ & $8,64 \%$ \\
\hline & $\begin{array}{l}\text { 4. Tidak meminta jawaban } \\
\text { kepada teman saat } \\
\text { ulangan }\end{array}$ & $59,26 \%$ & $17,28 \%$ & $23,46 \%$ \\
\hline \multirow[t]{3}{*}{ Jujur } & 5. Berkata jujur & $69,14 \%$ & $30,86 \%$ & $0,00 \%$ \\
\hline & $\begin{array}{l}\text { 6. Membayar hal (misal } \\
\text { jajanan) yang dibeli di } \\
\text { kantin sekolah }\end{array}$ & $59,26 \%$ & $22,22 \%$ & $16,05 \%$ \\
\hline & $\begin{array}{l}\text { 7. Menyimak dengan baik } \\
\text { pelajaran yang } \\
\text { disampaikan oleh ustadz } \\
\text { maupun ustadzah }\end{array}$ & $79,01 \%$ & $18,52 \%$ & $1,23 \%$ \\
\hline \multirow[t]{3}{*}{ Tekun } & $\begin{array}{l}\text { 8. Memiliki catatan pelajaran } \\
\text { yang lengkap sesuai } \\
\text { dengan yang telah } \\
\text { diberikan oleh ustadz } \\
\text { maupun ustadzah }\end{array}$ & $79,01 \%$ & $19,75 \%$ & $0,00 \%$ \\
\hline & $\begin{array}{l}\text { 9. Mengerjakan tugas yang } \\
\text { diberikan oleh ustadz } \\
\text { maupun ustadzah }\end{array}$ & $88,89 \%$ & $8,64 \%$ & $1,23 \%$ \\
\hline & $\begin{array}{l}\text { 10. Datang ke sekolah tepat } \\
\text { waktu } \\
\text { 11. Memakai seragam sekolah }\end{array}$ & $76,54 \%$ & $22,22 \%$ & $0,00 \%$ \\
\hline \multirow[t]{4}{*}{ Disiplin } & $\begin{array}{l}\text { sesuai peraturan yang } \\
\text { telah ditentukan dengan } \\
\text { rapi dan bersih }\end{array}$ & $95,06 \%$ & $4,94 \%$ & $0,00 \%$ \\
\hline & $\begin{array}{l}\text { 12. Melaksanakan tugas piket } \\
\text { sesuai jadwal }\end{array}$ & $76,54 \%$ & $20,99 \%$ & $0,00 \%$ \\
\hline & $\begin{array}{l}\text { 13. Membuang sampah pada } \\
\text { tempatnya }\end{array}$ & $71,60 \%$ & $23,46 \%$ & $1,23 \%$ \\
\hline & $\begin{array}{l}\text { 14. Memungut sampah yang } \\
\text { berserakan dan } \\
\text { membuangnya ke tempat } \\
\text { sampah }\end{array}$ & $33,33 \%$ & $60,49 \%$ & $6,17 \%$ \\
\hline \multirow{2}{*}{$\begin{array}{l}\text { Peduli } \\
\text { lingkungan }\end{array}$} & $\begin{array}{l}\text { 15. Membersihkan kamar } \\
\text { mandi setelah }\end{array}$ & & & \\
\hline & $\begin{array}{l}\text { menggunakannya } \\
\text { (mengguyur WC dengan } \\
\text { air bersih setelah buangair } \\
\text { kecil maupun besar) }\end{array}$ & $85,19 \%$ & $7,41 \%$ & $6,17 \%$ \\
\hline
\end{tabular}


SHEs: Conference Series 1 (2) (2018) 193-199

Tabel 2. Persentase rata-rata jawaban pernyataan selalu

\begin{tabular}{cc}
\hline Aspek & $\begin{array}{c}\text { Persentase } \\
\text { rata-rata }\end{array}$ \\
\hline Religius & $54,73 \%$ \\
Jujur & $62,55 \%$ \\
Tekun & $82,30 \%$ \\
Disiplin & $82,71 \%$ \\
Peduli lingkungan & $63,37 \%$ \\
\hline
\end{tabular}

Interval kriteria interpretasi skor :

- $0 \%-33 \%=$ buruk

- $34 \%-67 \%=$ cukup

- $68 \%-100 \%$ = baik

Berdasarkan data lembar angket siswa SDIT Ibnu Abbas diatas diperoleh hasil rata-rata persentase kegiatan yang selau dilakukan adalah sebagai berikut, aspek religius menempati persentase sebesar $54,73 \%$ dengan kategori "cukup" dan kegiatan yang paling banyak dilakukan adalah sholat dhuha di disekolah. Sedangkan perilaku jujur diperoleh persentase rata-rata sebesar 62,55\% dengan kategori "cukup" dan pernyataan berkata jujur yang mendominasi jawaban siswa. Selanjutnya perilaku tekun memperoleh persentase rata-rata sebesar $82,30 \%$ dengan kategori "baik" dan kegiatan mengerjakan tugas yang diberikan ustad/ ustadzah yang paling banyak dijawab siswa. Perilaku disiplin dengan persentase $82,71 \%$ dengan kegiatan yang paling sering dilakukan adalah memakai seragam sekolah sesuai peraturan yang telah ditentukan dengan rapi dan bersih. Yang terakhir adalah perilaku peduli lingkungan dengan persentase $63,37 \%$ yaitu membersihkan kamar mandi setelah menggunakannya (mengguyur wc dengan air bersih setelah buang air kecil maupun besar) yang paling banyak dilakukan siswa.

Penelitian selanjutnya yaitu wawancara yang mana dilakukan dengan kepala sekolah dan guru kelas. Berdasarkan hasil wawancara dapat diketahui bahwa kepala sekolah dan guru di SDIT Ibnu Abbas telah menyadari pentingnya pendidikan karakter bagi anak usia sekolah dasar. Kepala sekolah mengatakan, "Tanggung jawab pendidikan di sekolah dasar lebih banyak ke pendidikan karakter daripada pengetahuannya. Ketika karakter siswa telah terbentuk, insyaallah yang lainnya akan mengikuti" (Hasil wawancara kepala sekolah pada Jumat, 5 Oktober 2018 pukul 09.00). Sejalan dengan pendapat Sudaryanti (2012) dalam jurnal pendidikan anak vol.1 mengemukakan bahwa "Pendidikan karakter sangatlah penting untuk membangun peradaban bangsa, pendidikan karakter tersebut seharusnya sudah di tanamkan sejak anak usia dini sehingga mereka sangat tepat jika di jadikan komunitas awal pembentukan karakter karena anak berada pada usia emas (golden age)."

Pendidikan karakter di SDIT Ibnu Abbas sudah terimplementasi. Hal ini terlihat dari budaya tertentu di SD IT Ibnu Abbas Kebumen yang berkaitan dengan nilai religius, jujur, tekun, disiplin, dan peduli lingkungan. Perilaku religius terlihat dari adanya kegiatan rutin religius di sekolah, seperti shalat wajib berjama'ah di sekolah, shalat dhuha, berdoa sebelum belajar, mentoring, dan lain-lain. Menurut Naim (2012:125) tujuan menciptakan kegiatan rutin untuk menunjukkan pengembangan kehidupan religius di lembaga pendidikan yang tergambar dari perilaku sehari-hari dari berbagai kegiatan yang dialakukan oleh guru dan peserta didik.

Penanaman nilai jujur di SDIT Ibnu Abbas dengan memberi pengertian bahwa anak-anak boleh saja berbohong kepada guru tapi jangan berbohong kepada Allah dan diri sendiri. Hal ini sejalan dengan Naim (2012:134) mengenai memahamkan anak mengenai berbohong bahwa orang tua bisa menjelaskan bahwa sekali berbohong 
berarti melakukan tiga kebohongan sekaligus; bohong kepada orang lain,bohong kepada Allah, dan juga bohong kepada diri sendiri. Selain itu dengan lembar evaluasi shalat, siswa ditanya apakah mengerjakan shalat lima waktu atau tidak di rumah.

Perilaku tekun, misalnya pengarahan untuk rajin membaca buku cerita. Seperti yang diungkapkan Nur Hidayat (2016) mengenai implementasi pendidikan karakter melalui pembiasaan dikutip dari Sulaeman "kebiasaan belajar dapat diartikan sebagai cara-cara atau teknik-teknik yang mantap yang dilakukan siswa pada waktu ia menerima pelajaran dari guru, membaca buku dan mengerjakan tugas-tugas sekolah, serta pengaturan waktu untuk menyelesaikan kegiatan-kegiatan tersebut".

Perilaku disiplin SDIT Ibnu Abbas Kebumen yaitu siswa diharapkan datang sebelum guru berada di kelas. Sesuai dengan pendapat Naim (2012:146) bahwa ada beberapa bentuk kedisiplinan yaitu hadir di ruangan tepat pada waktunya, tata pergaulan di sekolah, dan engikuti kegiatan ekstrakurikuler. Di SDIT Ibnu Abbas diajarkan pula untuk disiplin saat mengambil snack dan makan siang sesuai dengan urutan siapa yang berangkat lebih pagi.

Manusia berkarakter adalah manusia yang memiliki kepedulian terhadap lingkungan, baik lingkungan sosial maupun lingkungan fisik (Naim, 2012:200). Maka dari itu, di SDIT Ibnu Abbas Kebumen diajarkan pula bagaimana agar siswa peduli terhadap lingkungannya. Perilaku peduli lingkungan dilihat dari budaya piket kelas, membuang sampah pada tempatnya, dan bahkan ada hukuman untuk mengambil sampah di selokan (bila ada) lalu dibuang di tempat sampah. Hal ini terlihat pula saat observasi, kelasnya bersih dan rapi.

SDIT Ibnu Abbas Kebumen memadukan antara kurikulum umum dengan pendidikan karakter keislaman dengan visi dan misi yang ingin dicapai yaitu Mandiri, Sholeh, dan Berprestasi. Beberapa nilai-nilai karakter yang hendak dicapai adalah nilai-nilai religius, jujur, tekun, disiplin, dan peduli lingkungan yang tercantum dalam Rencana Pelaksanaan Pembelajaran (RPP). Menurut salah satu guru kelas 5 mengatakan, "Penanaman nilai-nilai karakter tentu saja termuat dalam RPP yg kami buat seperti religius, jujur, tekun, disiplin, dan peduli lingkungan. Apalagi sekarang kurikulum yang digunakan adalah kurikulum K13 yang mengharuskan untuk memuat nilai-nilai karakter yang akan dicapai yang sebisa mungkin disampaikan saat proses pembelajaran di kelas" (wawancara pada 5 Oktober 2018 pukul 09.30).

Terealisasinya nilai-nilai ini tidak luput dari peran guru sebagai pendidik dan teladan bagi peserta didik. Selain itu, guru selalu berupaya untuk mendorong agar siswa mau menerapkan setiap nilai-nilai religius, jujur, tekun, disiplin, dan peduli lingkungan. Salah satu upayanya adalah dengan membuat aturan di kelas yang disepakati bersama dan tentu saja ada sanksi bagi siswa yang melanggarnya. Sifat guru yang tegas dalam menerapkan aturan juga menjadi point penting terlaksananya penanaman pendidikan karakter di SDIT Ibnu Abbas Kebumen.

Dalam proses penerapan nilai-nilai karakter terdapat pula faktor penghambat yang harus dihadapi oleh kepala sekolah dan guru. Berdasarkan hasil wawancara, hambatan pertama yang dialami oleh guru yaitu waktu pendampingan dengan siswa yang terkadang kurang karena tugas guru selain mendidik siswa juga harus memenuhi berbagai administrasi. Kedua, bahan ajar yang terbatas. Ketiga, yaitu faktor lingkungan rumah dan sekolah yang tidak selaras, misalnya ketika di sekolah karakter anak sudah terkontrol tetapi saat di rumah tidak. Karena pada hakikatnya usaha pembentukan karakter anak memang semestinya dilakukan oleh orang tua (Nasrullah, 2015).

Solusi yang diupayakan oleh guru dan kepala sekolah lebih kepada komunikasi antara guru dan siswa serta dengan orang tua siswa/wali. Komunikasi ini dilakukan agar setiap penanaman nilai religius, jujur, tekun, disiplin, dan peduli lingkungan yang ada di sekolah dapat sejalan dan mampu di terapkan di rumah dan masyarakat. Hal ini sejalan dengan Komite Pendidikan Karakter Nasional yang didirikan pada tahun 1997 di Amerika Serikat mendefinisikan pendidikan karakter sebagai "pendidikan yang 
direncanakan oleh personel sekolah dan membutuhkan komunikasi yang sering antara keluarga dan masyarakat, memungkinkan anak-anak untuk berhati-hati dan berprinsip (Williams dan Schnaps, 1999; Demirel, Demet, dan Imgehan, 2016)

\section{SIMPULAN}

Berdasrkan hasil dan pembahasan dapat diambil kesimpulan bahwa:

1. Penanaman nilai-nilai pendidikan karakter di SD Islam Terpadu Ibnu Abbas memadukan antara kurikulum umum dengan pendidikan karakter keislaman dengan visi dan misi yang ingin dicapai yaitu Mandiri, Sholeh, dan Berprestasi. Beberapa nilai-nilai karakter yang hendak dicapai adalah nilai-nilai religius, jujur, tekun, disiplin, dan peduli lingkungan yang tercantum dalam Rencana Pelaksanaan Pembelajaran (RPP).

2. Hasil observasi menunjukkan aspek religius 54,73\% dengan kategori "cukup", aspek jujur $62,55 \%$ dengan kategori "cukup", aspek tekun $82,30 \%$ dengan kategori "baik", aspek disiplin 82,71\% dengan kategori "baik", dan aspek peduli lingkungan $63,73 \%$ dengan kategori "cukup".

3. Hambatan yang dialami oleh guru adalah ketika penanaman yang diajarkan oleh guru tidak selaras dengan yang di rumah. Sehingga solusi yang diupayakan oleh guru yaitu dengan komunikasi dengan lebih dalam dengan siswa dan orang tua siswa/wali.

\section{DAFTAR PUSTAKA}

Agustina, S., Irawan S., dan Yunisca N. (2013). Peran Sekolah Terpadu Dalam Pembentukan Karakter Religius Siswa. diunduh dari http://jurnal.fkip.unila.ac.id/index.php/JKD/article/viewFile/771/484

Demirel, M., Demet O., dan Imgehan O.E. (2016). Primary school Teachers' Perceptions About Character Education. Academic Journals Vol. 11(17), pp. 1622-1633, 10 September 2016 ISSN 1990-3839

Hidayat, N. (2016) Implementasi Pendidikan Karakter Melalui Pembiasaan Di Pondok Pesantren Pabelan diunduh dari https://media.neliti.com/media/publications/70998-ID-implementasipendidikan-karakter-melalui.pdf

Kementrian Pendidikan dan Kebudayaan. (2016). Undang-undang No. 20 Tahun 2003 Tentang Sistem Pendidikan Nasional. Jakarta: Kementrian Pendidikan dan kebudayaan

Kesuma, D., Cepi T., dan Johar P. (2013). Pendidikan Karakter: Kajian Teori dan Praktik di Sekolah. Bandung: PT Remaja Rosdakarya

Naim, N. (2012). Character Building. Yogyajarta: Ar-Ruzz Media

Nasrullah. (2015). Pembentukan Karakter Siswa Melalui Pendidikan Agama Islam. SALAM Volume 18 No. 1, halaman 1-183, Malang, Juni 2015

Sofiawati, E.T dan Fadhillah. (2018). Penguatan Pendidikan Karakter Melalui Pendidikan agama Islam di Sekolah Dasar. Prosiding Seminar Nasional, "Penguatan Pendidikan Karakter Pada Siswa Dalam Menghadapi Tantangan Global" Kudus, 11 April 2018

Sudaryanti, S. (2012). Pentingnya Pendidikan Karakter bagi Anak Usia Dini. Diunduh dari https://journal.uny.ac.id/index.php/ipa/article/view/2902/2416

Suryadi, B. (2017). Perpres PPK dan Posisi Standar Nasional Pendidikan Dalam Penguatan Pendidikan Karakter. Buletin BSNP

Thapa, A dan Jonathan C. (2013). A Review of School Climate Research. Review of Educational Research September 2013, Vol. 83, No. 3, pp. 357-358 DOI:10.3102/0034654313483907 